\title{
Trivalent Metal Adsorption Properties on Synthesized Viscose Rayon Succinate
}

\author{
By Aruukhan Dashkhuu KHASBAATAR, ${ }^{1}$ Yong Jin $\mathrm{CHUN}^{2}$ and Ung Su CHOI ${ }^{1, *}$
}

\begin{abstract}
A viscose rayon succinate (VRS) was synthesized using viscose rayon, succinic anhydride and DMSO. The VRS was well characterized by $\mathrm{C}^{13}$ nuclear magnetic resonance, Fourier transform infrared analysis and properties of the VRS up taking trivalent metals from aqueous solution were investigated. Both esterification and carboxyl bonding of the VRS were assigned essentially at 1729 and $1693 \mathrm{~cm}^{-1}$, respectively. And the essential band of bonding between metal and the material was determined at $1605-1639 \mathrm{~cm}^{-1}$. The available adsorption capacity, degree of substitution and $\mathrm{p} K \mathrm{a}$ of the VRS were 6.2 mequiv/g, 2.5 and 3.72, respectively. The adsorption of metal ions on the VRS follows the order of $\mathrm{Cr}^{3+}>\mathrm{Al}^{3+}>\mathrm{Fe}^{3+}$ with maximum adsorptions capacities $1.48,1.059$ and $1.029 \mathrm{mmol} / \mathrm{g}$. An equilibrium modeling, which is obtained from chemical potential and Boltzmann distribution, was demonstrated trivalent metal adsorption on the VRS in different pHs. Surface potential, $\Psi_{0}$, an effective ratio of surface equilibrium constants, $K_{\text {effect }}$, the probability factor $P(A)$ and a degree of protonation, $\chi$ represent the physicochemical interactions between carboxyl group and metal ions.
\end{abstract}

KEY WORDS: Chelating Fiber / Viscose Rayon / Metal Adsorption / Carboxyl Group / FT-IR / Adsorption Modeling /

Fibers have been used in many applications due to their advantages and properties such as high adsorption capacity, and good electrical conductivity. ${ }^{1}$ A fiber type of viscose rayon (VR) is a kind of regenerated cellulose which is abundant and easily accessible biopolymer probably suitable for developing novel type of materials with various advanced functions. ${ }^{2}$ The most known method of modification of cellulose is esterification that can increase a number of applications. Also, inorganic and organic esters of cellulose played an important role in coating applications. ${ }^{3}$

Some cellulose esters which functional groups have been introduced into them, have been employed successfully in some areas such as removal of harmful trace metal ions, because of their highly selective adsorptivity for heavy metal ions. ${ }^{4}$ Trivalent heavy metal ions (THM) such as $\mathrm{Al}^{3+}, \mathrm{Cr}^{3+}$, and $\mathrm{Fe}^{3+}$ in aqueous solution are toxic to all living organisms including human beings, microbes, plants, fish, and mammals. ${ }^{5-7}$ Especially, the toxicity $\mathrm{Al}^{3+}$ in drinking is well reported, and its involvement to Alzheimer's disease has been documented. ${ }^{8,9}$ Even though $\mathrm{Cr}^{3+}$ is an essential nutrient, its oxidation to toxic $\mathrm{Cr}^{6+}$ can cause lung cancers and ecological problems. ${ }^{9,10}$ In drinking water supplement, iron is a common and troublesome mineral due to the corrosion of iron pipes. This contaminant is often the cause of taste, odor, discoloration, and turbidity problems. Moreover, the issue of the corrosion is more concerned than groundwater contamination. ${ }^{11}$ Accordingly, the treatment of heavy metals from wastewater, and soil has been required to reduce the metal concentration to less than that designated values which is in environmental regulations. Various efficient methods and technologies are developed for their removal. One of well known methods is to adsorb heavy metals from aqueous solution using chelating fibers. ${ }^{12}$
The physico-chemical mechanisms involved in metal removal such as physical adsorption, ion-exchange and surface complexation can be investigated to optimize the operating conditions, product development and process design. ${ }^{13}$

The most important environmental factor is $\mathrm{pH}$ which influences not only the site dissociation, but also the solution chemistry of the heavy metals: hydrolysis, complexation by organic and/or inorganic ligands, redox reactions and precipitation are strongly influenced by $\mathrm{pH}$ and, also the speciation and the adsorption availability of the heavy metals are strongly influenced. ${ }^{14,15}$

The aim of this study is to investigate THM adsorption at different $\mathrm{pHs}$ and thermal stability of the VRS coupled with THM (VRS-M). We examined the synthesis and structure of the VRS, the VRS-M using Fourier transform infrared (FT-IR) spectroscopy, ${ }^{13} \mathrm{C}$ solid state nuclear magnetic resonance (NMR), field-emission scanning electron (FE-SEM) microscopy, and thermal properties were examined by thermogravimetric analysis (TGA). Also, adsorption equilibrium of trivalent metal ions $\left(\mathrm{Al}^{3+}, \mathrm{Fe}^{3+}\right.$, and $\left.\mathrm{Cr}^{3+}\right)$ on the VRS was investigated. Then the models were used to describe the experimental isotherms.

\section{EXPERIMENTAL}

\section{Materials}

The VR felt was purchased from Sechang Chemical Co. (Incheon, Korea,). Succinic anhydride $\left(\mathrm{C}_{4} \mathrm{H}_{4} \mathrm{O}_{3}\right.$; DaeJung Chemicals \& Metals Co., Ltd., Korea; $\geq 99 \%$ pure), dimethylsulfoxide (DMSO) $\left(\left(\mathrm{CH}_{3}\right)_{2} \mathrm{SO}\right.$; DaeJung Chemicals \& Metals Co., Korea; $\geq 99.5 \%)$, iron chloride hexahydrate $\left(\mathrm{AlCl}_{3} \cdot 6 \mathrm{H}_{2} \mathrm{O}\right.$; DaeJung Chemicals \& Metals Co., Korea; $\geq 97.9 \%$ ), chromium

\footnotetext{
${ }^{1}$ Energy Mechanics Research Center, Korea Institute of Science and Technology, P.O.Box 131, Cheongryang, Seoul 130-650, Korea

${ }^{2}$ Dept. of New Mater. \& Appl. Chemistry, Chung Woon University, San 29, Namjang-ri, Hongung-gun 350-701, Korea

*To whom correspondence should be addressed (Tel: +82-2-958-5657, Fax: +82-2-958-5659, E-mail: uschoi@ kist.re.kr).
} 
(a)

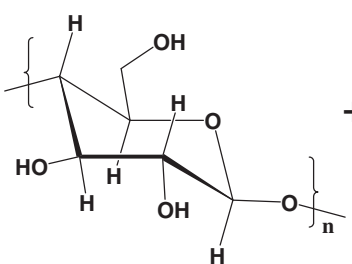

Cellulose viscose rayon

(felt)

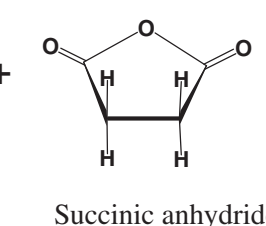

Succinic anhydride

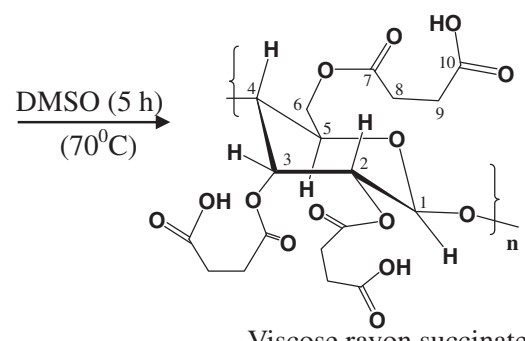

Viscose rayon succinate

(b)

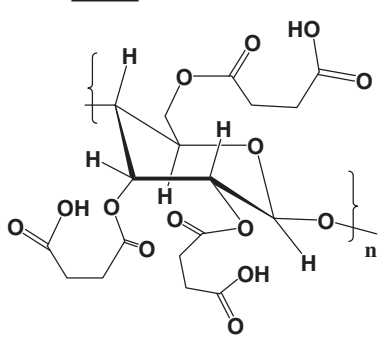

Water with metal ions

Viscose rayon succinate
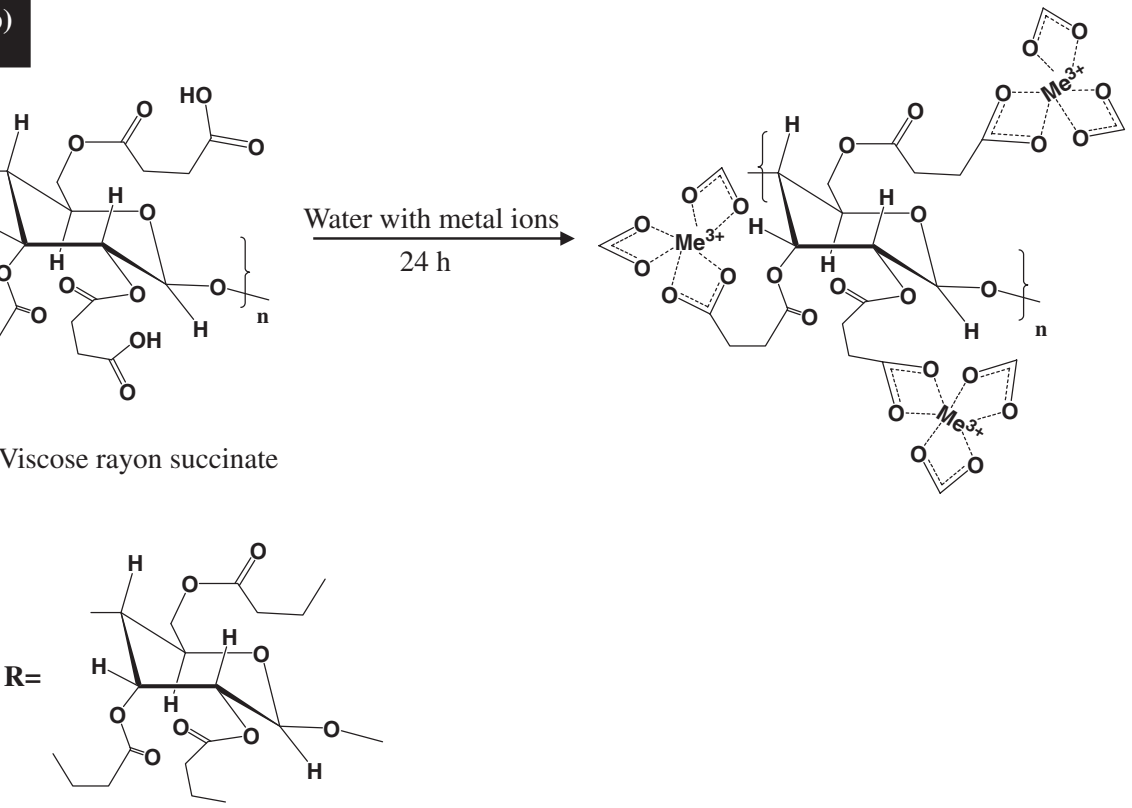

Figure 1. Schematic of synthesizing mechanism of (a) VRS, (b) VRS with metal adsorbed.

chloride hexahydrate $\left(\mathrm{CrCl}_{3} \cdot 6 \mathrm{H}_{2} \mathrm{O}\right.$; Sigma Chemical Co.; $\geq 99 \%$ pure), and aluminum chloride hexahydrate $\left(\mathrm{AlCl}_{3}\right.$. $6 \mathrm{H}_{2} \mathrm{O}$; DaeJung Chemicals \& Metals Co., Korea; $\geq 97.9 \%$ ) were used without further purification. Sigma supplied $0.1 \mathrm{~N}$ natrium hydroxide $(\mathrm{NaOH}), 0.1 \mathrm{~N}$ hydrochloric acid $(\mathrm{HCl})$ and $0.1 \mathrm{~N}$ nitric acid $\left(\mathrm{HNO}_{3}\right)$.

\section{Preparation of the VRS}

The VRS was obtained through the heating the VR felt $(10 \mathrm{~cm} \times 10 \mathrm{~cm}, 5 \mathrm{~g}$ and $2.8 \mathrm{~mm}$ thick) with succinic anhydrate $(30 \mathrm{~g})$, and DMSO $(500 \mathrm{~g})$ in a round flask with a condenser at $70{ }^{\circ} \mathrm{C}$ for $5 \mathrm{~h}$ with stirring. The synthesized the VRS was washed with both cold and hot distilled water and dried in a freeze dryer for $24 \mathrm{~h}$. Figure 1(a) shows the chemical structure and the numbering of the carbon atoms of the VRS.

${ }^{13} \mathrm{C}$ NMR (solid state): $\delta=105$ (C1), 74.8 (C2), 73 (C3), 88 (C4), 90 (C5), 63.5 (C6), 173.8 (C7), 29.9 (C8), 39.8 (C9), and 176 (C10).

\section{Capacity of the VRS}

An acid-base titration method was used to determine the cation exchange capacity of the VRS. Exactly $100 \mathrm{~mL}$ of $0.1 \mathrm{~N}$
$\mathrm{NaOH}$ solution were added to a $100 \mathrm{~mL}$ Erlenmeyer flask with $0.1 \mathrm{~g}$ of the VRS and shaken for $24 \mathrm{~h}$ at $200 \mathrm{rpm}$ at room temperature. After being shaken, three $25 \mathrm{~mL}$ samples were extracted from the shaken solution and measured using an autotitrator utilizing a $0.1 \mathrm{~N} \mathrm{HCl}$ solution. The average value of the cation exchange capacity from the sampled solutions was $6.2 \mathrm{meq} / \mathrm{g}$.

$$
\begin{gathered}
\mathrm{R}-\mathrm{COOH}+\mathrm{NaOH} \Leftrightarrow \mathrm{R}-\mathrm{COONa}+\mathrm{H}_{2} \mathrm{O} ; \\
q_{e}=\frac{\left(V_{25}-V_{\mathrm{HCl}}\right) C_{\mathrm{NaOH}} V_{100}}{M V_{25}}
\end{gathered}
$$

Where $q_{e}$, is the cation exchange capacity, $\mathrm{R}$ is shown in Figure $1, M$ is the mass of the VRS, $V_{100}$ is the volume of the solution, $V_{25}$ is the volume sampled from the solution, $V_{\mathrm{HCl}}$ is the volume of $\mathrm{HCl}$ used for back titration, and $C_{\mathrm{NaOH}}$ is the initial concentration of $\mathrm{NaOH}$ in the solution.

\section{Degree of Substitution (DS) of the VRS}

In order to determine the DS of VRS, the same method as obtaining adsorption capacity of VRS was applied. So, ester content was calculated as: 


$$
\mathrm{EC}(\%)=\frac{\left(V_{25}-V_{\mathrm{HCl}}\right) C_{\mathrm{NaOH}} M_{\mathrm{sa}}}{10 M}
$$

where $M_{\mathrm{sa}}$ is the molecular weight of grafted succinic residue.

The degree of substitution was then calculated as:

$$
\mathrm{DS}={\frac{162 \mathrm{EC}}{100 M_{\mathrm{sa}}-\mathrm{EC}\left(M_{\mathrm{sa}}-1\right)}}^{16}
$$

where 162 is the molecular weight of anhydroglucose. The degree of substitution (DS) was 2.5.

\section{pKa of the VRS}

$0.5 \mathrm{~g}$ of VRS was protonated by $10 \mathrm{~mL}$ of water. Then, it was potentiometrically titrated with $0.1 \mathrm{NaOH}$ using an autotitrator. The $\mathrm{pK}$ a was obtained by the well-known equation of Henderson.

$$
\mathrm{pH}=\mathrm{p} K \mathrm{a}+\log \frac{\left[\mathrm{A}^{-}\right]}{[\mathrm{HA}]}
$$

$\mathrm{pH}=\mathrm{pK}$ a occurs due to the fact that $\left[\mathrm{A}^{-}\right]$is equal to [HA] at the half-neutralization points. ${ }^{17}$ The value of the $\mathrm{p} K \mathrm{a}$ is 3.72 .

\section{Quantitative Analysis of the Adsorption of $\mathrm{Al}^{3+}, \mathrm{Fe}^{3+}$, and} $\mathrm{Cr}^{3+}$

A hundred $\mathrm{ml}$ of $\mathrm{pH}$ adjusted solutions containing $10 \mathrm{mM}$ each of $\mathrm{Al}^{3+}, \mathrm{Fe}^{3+}$, and $\mathrm{Cr}^{3+}$, and $0.1 \mathrm{~g}$ of the VRS were placed in Erlenmeyer flasks and shaken for $24 \mathrm{~h}$ at $200 \mathrm{rpm}$. After removed the VRS from the solution, the concentration of metal not removed from the solution was determined by an atomic absorption spectrometer (AAS.) The VRS with metal was dried at $40{ }^{\circ} \mathrm{C}$ in a vacuum oven for $24 \mathrm{~h}$ and characterized by a FTIR spectrometer. Concentrated $\mathrm{HCl}$ was used to adjust the $\mathrm{pHs}$ of the metal ion aqueous solutions.

\section{Measurements}

FT-IR spectra (4000-200 $\mathrm{cm}^{-1}, \mathrm{KBr}$ disc) were recorded on a GX FT-IR PerkinElmer spectrometer. ${ }^{13} \mathrm{C}$ NMR spectra were obtained on a Bruker MSL200 spectrometer in the solid state. The VRS-Al and mapping of aluminum were observed in a FE-SEM (Hitachi S4200) at $15.0 \mathrm{kV}$. An atomic absorption spectrometer (AAS; SpectraAA 800, Varian, USA) and inductively coupled plasma (ICP) mass spectrometer (Polyscan 61E, Theromo Jarrell Ash) were used for quantitative analyses of the quantitative analysis of adsorbed ions. TGA were carried out with a DuPont 951 thermogravimetric analyzer. The TGA curves were obtained under a nitrogen atmosphere at a flow rate of $4 \mathrm{~mL} / \mathrm{min}$ and scanning rate of $10^{\circ} \mathrm{C} / \mathrm{min}$. The adsorption capacity, DS, $\mathrm{pKa}$ of the VRS and the $\mathrm{pH}$ values were measured using an auto-titrator (Metrohm 728, Switzerland), and pH 300 (Hanna Instruments, Italy) digital $\mathrm{pH}$ meter, respectively.

\section{RESULTS AND DISCUSSIONS}

\section{Surface Characterization of Modified the VR}

FT-IR spectra of the VR, and the VRS are recorded in the 4000 to $500 \mathrm{~cm}^{-1}$ region and the characteristic bands are shown in Figure 2(a) and 2(b). The main difference of FT-IR spectra between the VR and the VRS was that bonding effects

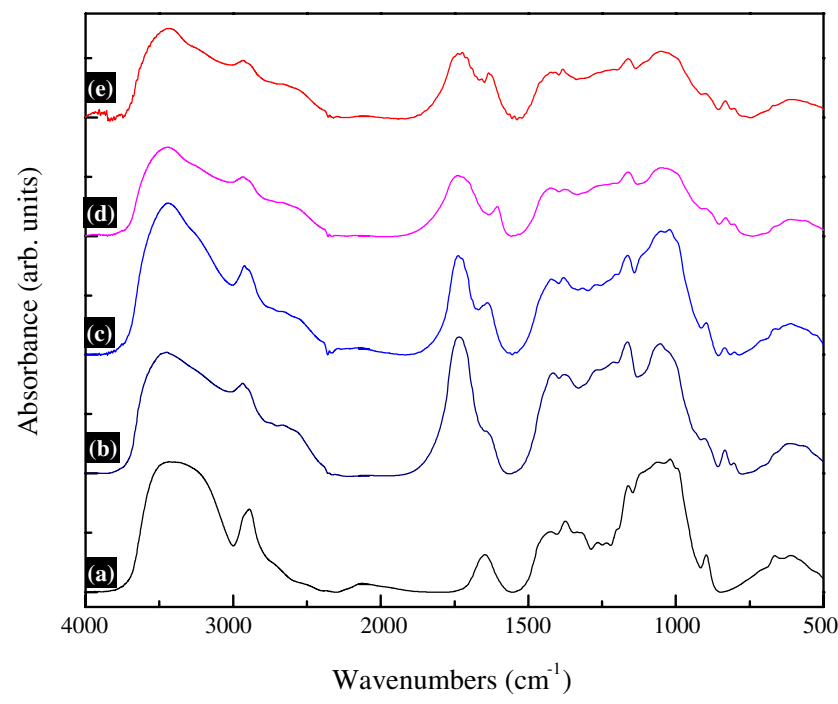

Figure 2. FT-IR spectra of (a) VR, (b) VRS, and VRS with trivalent metal ion complexes: (c) $\mathrm{Cr}^{3+} 1.48 \mathrm{mmol} / \mathrm{g}$ (d) $\mathrm{Al}^{3+} 1.05 \mathrm{mmol} / \mathrm{g}$ (e) $\mathrm{Fe}^{3+}$ $1.01 \mathrm{mmol} / \mathrm{g}$.

of carboxyl appeared in the spectrum of the VRS and did not appear the spectrum of the VR. A broad and intense band in the $3000-3700 \mathrm{~cm}^{-1}$ region was assigned to free and hydrogen bonded $\mathrm{OH}$ stretching vibration of the VR. Due to carboxylic acid dimers in the VRS, the broad band was extended to $2400 \mathrm{~cm}^{-1}$ and exhibited more intense in the region of 3150 $2400 \mathrm{~cm}^{-1}$. The asymmetric $\mathrm{CH}_{2}$ stretching vibration for the VR appeared near $2891 \mathrm{~cm}^{-1}$. The VRS were characterized by the absorption of a symmetrical band around $2930 \mathrm{~cm}^{-1}$ that was attributable to $\mathrm{CH}_{2}$ groups and this band was shifted to higher wavelength from $2891 \mathrm{~cm}^{-1}$ which was assigned to $\mathrm{CH}_{2}$ on the VR. ${ }^{18}$ It might be elucidated that $\mathrm{CH}_{2}$ groups of succinic group on the VRS may be presented as indicative of $\mathrm{CH}_{2}$ on aliphatic group which was observed near $2930 \mathrm{~cm}^{-1}$. A band appeared at $834 \mathrm{~cm}^{-1}$ was assigned to wagging (out of plane bending) vibrations of carboxyl groups of the VRS.

Water absorption in the VR was observed at $1644 \mathrm{~cm}^{-1}$. In the spectrum of the VRS, very strong peaks carboxyl and carbonyl were appeared at $1734 \mathrm{~cm}^{-1}$ which is attributed to $\mathrm{C}=\mathrm{O}$ stretching bands. The peak at $1163 \mathrm{~cm}^{-1}$ attributed to $\mathrm{C}-\mathrm{O}$ stretching in the esters $\left(\mathrm{O}-(\mathrm{C}=\mathrm{O}) \mathrm{CHCH}_{2}\right)$ on the VRS were overlapped on the peak at $1160 \mathrm{~cm}^{-1}$ that was exhibited on the VR.

The FT-IR spectra of $\mathrm{Al}, \mathrm{Fe}$, and $\mathrm{Cr}$ adsorbed on the VRS were carried out as shown Figure 2. In the investigation of all metal adsorptions, the spectra reveal the presence of coordinated water molecules that indicated by broad bands at 3400$3465 \mathrm{~cm}^{-1}$. This peak was attributed to stretching vibrations of the $\mathrm{OH}$ groups of water molecules. When the metal complexes were derived from carboxylic acids and metal ions, the $\mathrm{C}=\mathrm{O}$ and $\mathrm{C}-\mathrm{O}$ were replaced by two equivalent carbon-oxygen bonds which are intermediate in force constant between the $\mathrm{C}=\mathrm{O}$ and $\mathrm{C}-\mathrm{O}$. The intensities of dimer bonding, which took place at $2400-3200 \mathrm{~cm}^{-1}$, were decreased due to complexation of metal adsorption of VRS. These bonds were strongly 


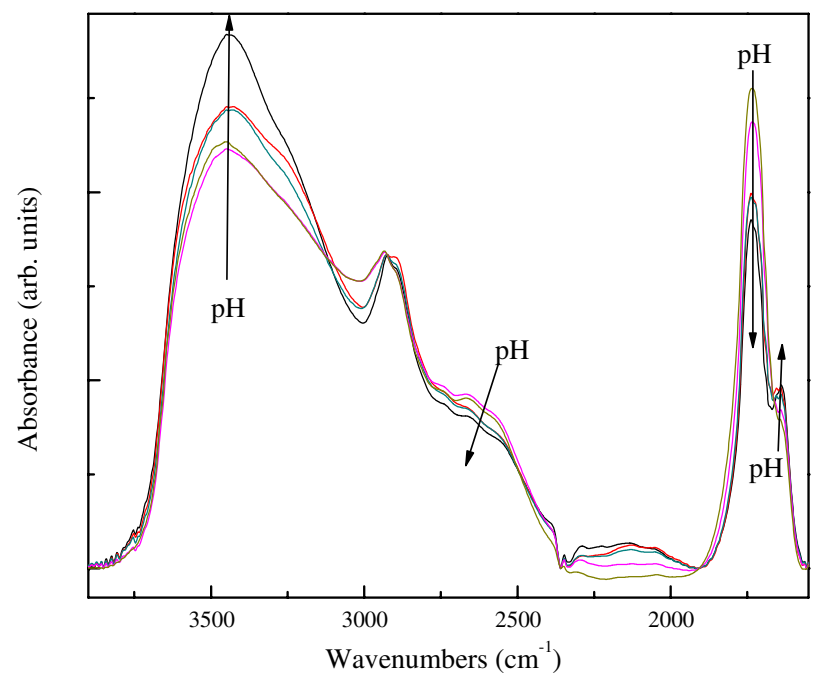

Figure 3. The comparison of FT-IR spectra of VRS $\mathrm{Cr}^{3+}$ increasing $\mathrm{pH}$.

coupled resulting in strong asymmetric $\mathrm{CO}_{2}$ stretching vibrations at $1605 \mathrm{~cm}^{-1}, 1635 \mathrm{~cm}^{-1}$, and $1639 \mathrm{~cm}^{-1}$ which were corresponded to carboxyl ion groups with metals such as $\mathrm{Al}^{3+}$, $\mathrm{Fe}^{3+}$, and $\mathrm{Cr}^{3+}$, respectively. Therefore, these peaks were shifted to lower wavelength than the peak of original carboxyl groups due to the bonds between carboxyl groups and metals that could reduce to double bonding property of carbonyl groups and caused to weaken the frequency of the double bond.

\section{FT-IR Study on $\mathrm{Cr}^{3+}$ with Various pHs}

Figure 3 shows the FT-IR spectra of $\mathrm{Cr}^{3+}$ adsorbed on the VRS with increasing $\mathrm{pH}$. The intensity of the broad band at $2400-3200 \mathrm{~cm}^{-1}$, which was associated with carboxylic acid dimers, decreased when the amount of metal ions adsorbed on the VRS increased. Moreover, it is interesting that an intensity of broad band in the region from $3600 \mathrm{~cm}^{-1}$ to $3100 \mathrm{~cm}^{-1}$ increased with rising $\mathrm{pH}$. It might be dealt with that the amount of hydrate bonding depended on adsorbed metal ions on the VRS. Since the alteration peak of $\mathrm{COOH}$ is a useful indicator for monitoring the organizational changes of metal adsorption. It can be seen in Figure 3 that some $\mathrm{COOH}$, which peaked at $1739 \mathrm{~cm}^{-1}$, switched to $\mathrm{COO}^{-}$which peaked at $1639 \mathrm{~cm}^{-1}$. Therefore, the intensity of the peak at $1739 \mathrm{~cm}^{-1}$ decreased. By contrast, as $\mathrm{pH}$ decreased, the intensity of the peak occurring at $1739 \mathrm{~cm}^{-1}(\mathrm{COOH})$ increased due to the switching of fewer ionic bonds between $\mathrm{COO}^{-}$and $\mathrm{Cr}^{3+}$.

SEM images in Figure 4 show (a) the VRS-Al and the corresponding (b) Al mapping images by EDS. Figure 4(a) shows a typical the VR image. The mapping of aluminum Figure 4(b) shows that the elements, within the magnification used, are well dispersed on the matrix surface. The Al emission line, observable as white dots, is at $1.475 \mathrm{keV} .{ }^{19}$ In the SEM images, no degradation was observed on fiber type of VRS-Al after synthesizing VRS. Fiber type ion exchanger and chelating agents have the high specific surface areas that contribute to the much higher adsorption rate and adsorption capacity of fibrous agents than resin type of ion exchanger. ${ }^{12}$
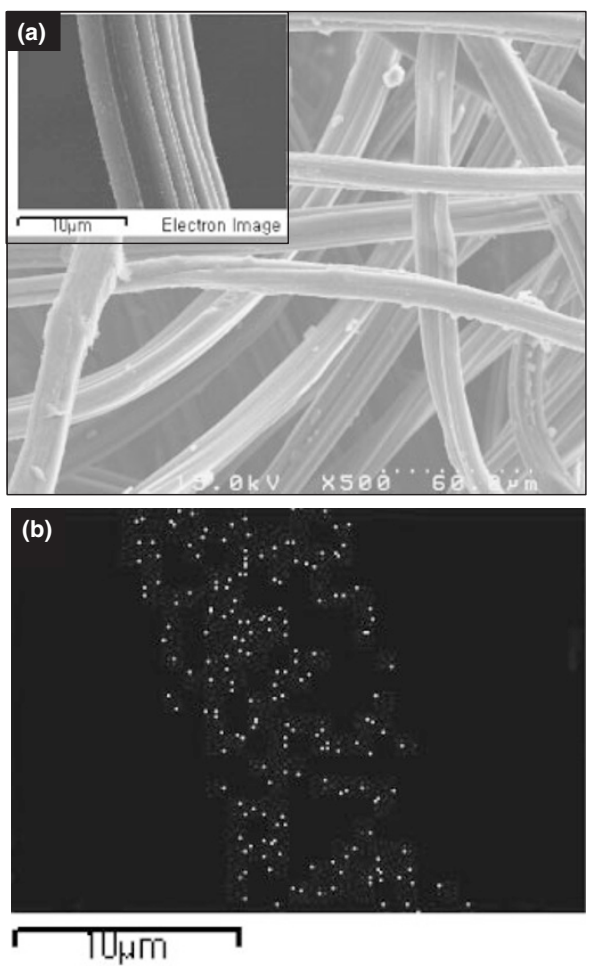

Figure 4. SEM images of (a) VRS-Al and the corresponding EDS Al mapping image (b). The Al emission line appears as white points.

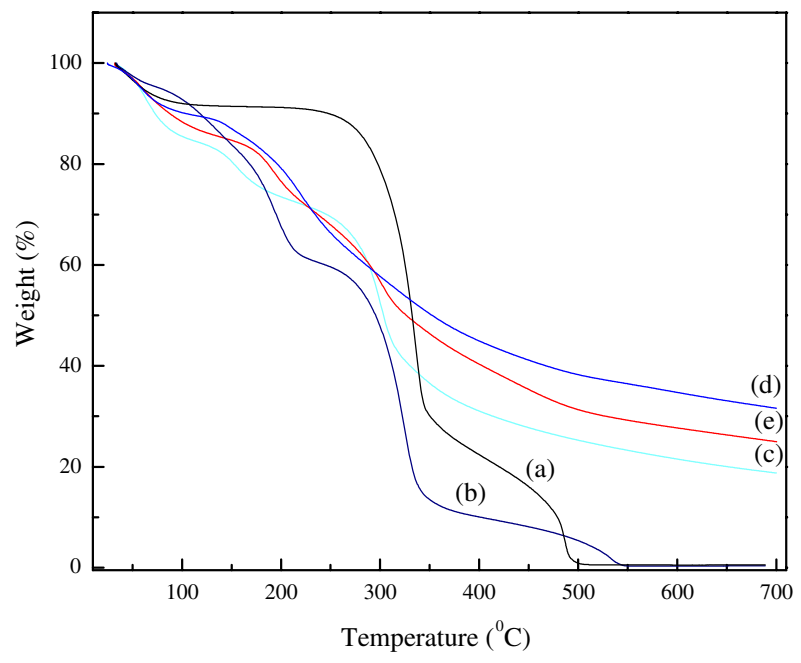

Figure 5. TGA curves of (a) VR, (b) VRS, and VRS with metals (c) VRS-Al, (d) VRS-Fe, and (e) VRS-Cr.

\section{Studies of Thermal Properties}

Figure 5 shows TGA curves of modified viscose rayons. TGA curves were obtained under a nitrogen atmosphere at a heating rate of $10^{\circ} \mathrm{C} / \mathrm{min}$. The TGA curve of the VR shows two main steps of weight loss behavior. The first weight loss occurred at $90^{\circ} \mathrm{C}$. This weight loss was caused by the volatilization of volatile matter and/or the evaporation of residual absorbed moisture. For viscose rayon, dehydration was taken place in a temperature range of $90-270^{\circ} \mathrm{C}$, thermal degradation occurred rapidly at $270{ }^{\circ} \mathrm{C}$, and char was formed at 
$343^{\circ} \mathrm{C}$. However, this char was not an original felt form. Most of the viscose rayon degraded at this temperature. In the case of the VRS, thermal degradation could be divided into three steps. First step was as if the first step of other samples. But the second step of weight loss occurred right after the first step because of the dehydration of the viscose rayon and it ended at $212{ }^{\circ} \mathrm{C}$. The presence of the succinic groups on the VR influenced thermostability of the VR to be decreased. It was probably forced by the liquid matrix of dehydration of succinic group, which is derived above $105^{\circ} \mathrm{C}$ and higher melting point of succinic acid around $200^{\circ} \mathrm{C}$ causes to decompose with melting. ${ }^{20}$ Third step started at $247^{\circ} \mathrm{C}$ and ended $341^{\circ} \mathrm{C}$ and represented the main thermal degradation of the viscose rayon succinate chains. Since the third step, the carbonization of the products was derived to ash.

Figure 5 also shows TGA curves of VRS metal complexes such as (c) VRS-Al, (d) VRS-Fe, and (e) VRS-Cr as well. Dehydration step of the VRS metal complexes might absorb some extent of heat and the melting temperature of succinic group was occurred at $95^{\circ} \mathrm{C}$. After dehydration step, a metal complex was decomposed at the temperature range of 95$287^{\circ} \mathrm{C}$ with similar of each others. Char formation step of thermal degradation did not occur rapidly. The VRS metal complexes with $\mathrm{Al}, \mathrm{Fe}$, and $\mathrm{Cr}$ showed $19 \%, 25 \%$, and $31 \%$ of ash formation at $700{ }^{\circ} \mathrm{C}$, respectively. It is considered that not only the boundaries of the three steps depended on the nature of the complexes but also concentration of metals in VRS metal complexes. Metal hydrates were thought to decompose into its constituents, with the absorption of heat. ${ }^{21}$ Therefore, heat transfer to the portion near the metals in VRS complexes is reduced even though temperature is increasing. The contents of metals in VRS metal complexes were as followed: $1.029 \mathrm{mmol}$ of Fe, $1.059 \mathrm{mmol}$ of $\mathrm{Al}$ and $1.48 \mathrm{mmol}$ of $\mathrm{Cr}$ in $1 \mathrm{~g}$ of VRS-Fe, VRS-Al and VRS-Cr, respectively. The shape of thermal degradations of VRS metal complexes was different as observed in Figure 5 due to the fact that the amounts of metals in VRS metal complexes were not same as each other. In the case of the VRS-Fe and VRS-Al, the difference of metal contents was negligible $(0.03 \mathrm{mmol} / \mathrm{g})$. However, the ash residue of VRS-Fe is higher than the ash residue of VRS-Al because of the difference between atomic weight of $\mathrm{Fe}$ and $\mathrm{Al}$ (the atomic weight of $\mathrm{Fe}$ is more than double of the $\mathrm{Al}$ ).

Study on Quantitative Analysis of the Adsorption of $\mathrm{Al}^{3+}$, $\mathrm{Fe}^{3+}$, and $\mathrm{Cr}^{3+}$

Figure 6 shows the quantitative analyses of trivalent metals adsorbed on the VRS with increasing $\mathrm{pH}$. The difference in the curves might be explained by the inherent chemical and physical properties of heavy metal ions. As the $\mathrm{pH}$ increased, the behavior of the VRS showed a more pronounced reactivity with the metals. In an acid medium, the VRS was highly protonated, and this characteristic reduced the attracting effect of the metal ion due to the lack of negative charges. In particularly for the carboxyl groups, adsorption phenomenon can occur in spite of the $\mathrm{pKa}$ being higher than $\mathrm{pH}$ of the medium. ${ }^{15}$ Metal adsorption was found to be significantly

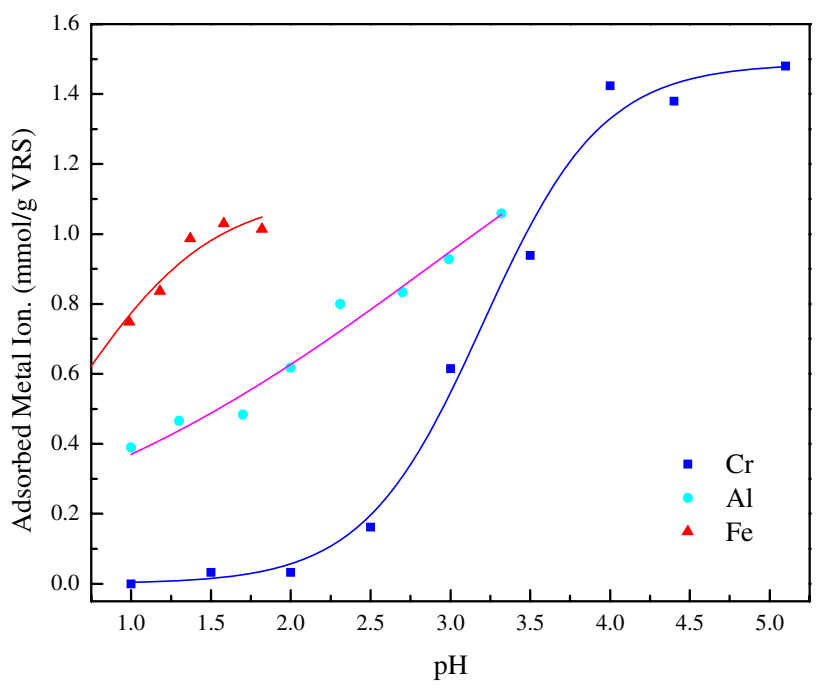

Figure 6. Experimental data and model plotting for cation adsorptions on VRS with increasing $\mathrm{pH}$.

influenced by the solution $\mathrm{pH} .1 .48 \mathrm{mmol}$ of $\mathrm{Cr}^{3+}$ in a 1 liter aqueous solution adsorbed on a gram of the VRS at $\mathrm{pH} 4$ represented the maximum adsorption. As seen in Figure 6, the maximum adsorptions of metal ions can be ordered as $\mathrm{Cr}^{3+}>\mathrm{Al}^{3+}>\mathrm{Fe}^{3+}$. However, at the same $\mathrm{pH}$ values, adsorptions of metal ions also classified as $\mathrm{Fe}^{3+}, \mathrm{Al}^{3+}$, and $\mathrm{Cr}^{3+}$. The order of metal adsorption was determined by the methodology outlined in section 3.6 using the factors, $P(A)$, $K_{\text {effect. }}$, and $\chi$ which were obtained from the equilibrium model of each of the metal adsorptions.

\section{Equilibrium Model for Cation Adsorption on the VRS}

Equilibrium structural properties of solutions and the VRS which is randomly tangled polymer In the experimental data, not all carboxyl groups on the VRS were covered by the metal ions.

This indicates that adsorption depended on the interaction between the VRS, which consists of intrinsically flexible chains which stay flexible on small length scales, and the behavior of metal ions. In water, protons of carboxyl groups on the VRS dissociated and the carboxyl groups became ionized. This reaction demonstrates that the carboxylic ions can bond with metal ions to form a neutral species and establish equilibrium. This result can be described by the following chemical equilibriums:

$$
\begin{aligned}
& \mathrm{RCOOH} \leftrightarrow \mathrm{RCOO}^{-}+\mathrm{H}^{+} \\
& 3 \mathrm{RCOO}^{-}+\mathrm{Cr}^{3+} \leftrightarrow(\mathrm{RCOO})_{3} \mathrm{Cr}
\end{aligned}
$$

Since we assume that both $\mathrm{RCOO}^{-}$and $(\mathrm{RCOO})_{3} \mathrm{Cr}$ groups are confined to the surface, we carefully considered the entropy of the mixing contribution to the free energy. ${ }^{22}$ The chemical potential of a surface group can be written as:

$$
\begin{aligned}
\mu_{\mathrm{RCOO}^{-}}= & \mu_{\mathrm{RCOO}^{-}}^{\theta}(\text { surface }) \\
& +\mu_{\mathrm{RCOO}^{-}}(\text {entropy of mixing })+\mu_{\mathrm{RCOO}^{-}}^{e l}
\end{aligned}
$$


If we assume a random (ideal) mixing of $\mathrm{RCOO}^{-}$and $\mathrm{Cr}^{3+}$ groups, the entropic term becomes

$$
\mu_{\mathrm{RCOO}^{-}} \text {(entropy of mixing) }=k T \ln X_{\mathrm{RCOO}^{-}}
$$

where

$$
X_{\mathrm{RCOO}^{-}}=\frac{3 n_{\mathrm{RCOO}^{-}}}{3 n_{\mathrm{RCOO}^{-}}+n_{(\mathrm{RCOO})_{3} \mathrm{Cr}}}
$$

Similarly, for the neutral $\mathrm{RCOOH}$ and $(\mathrm{RCOO})_{3} \mathrm{Cr}$ groups with surface mole fraction $X_{\mathrm{RCOOH}}$ and $X_{(\mathrm{RCOO})_{3} \mathrm{Cr}}$ we have:

$$
\begin{aligned}
& \mu_{\mathrm{RCOOH}}=\mu_{\mathrm{RCOOH}}^{\theta}(\text { surface })+k T \ln X_{\mathrm{RCOOH}} \\
& \mu_{(\mathrm{RCOO})_{3} \mathrm{Cr}}=\mu_{(\mathrm{RCOO})_{3} \mathrm{Cr}}^{\theta}(\text { surface })+k T \ln X_{(\mathrm{RCOO})_{3} \mathrm{Cr}}
\end{aligned}
$$

The electrostatic contribution, $\mu_{\mathrm{RCOO}^{-}}^{e l}$, to the chemical potential of the charged surface group represents the free energy required to bring a charge $z_{\mathrm{RCOO}^{-}} e$ from the bulk surface. This amounts to:

$$
\mu_{\mathrm{RCOO}^{-}}^{e l}=z_{\mathrm{RCOO}^{-}} e \Psi_{0}
$$

The chemical potential of the ion $\mathrm{H}^{+}$and $\mathrm{Cr}^{3+}$ is uniform and assumes ideal solution behavior.

$$
\begin{aligned}
& \mu_{\mathrm{H}^{+}}=\mu_{\mathrm{H}^{+}}^{\theta} \text { (solution) }+k T \ln C_{\mathrm{H}^{+}} \\
& \mu_{\mathrm{Cr}^{3+}}=\mu_{\mathrm{Cr}^{3+}}^{\theta}(\text { solution })+k T \ln C_{\mathrm{Cr}^{3+}}
\end{aligned}
$$

By requiring that chemical potentials are equal for the leftand right-hand sides of equations 1 and 2, we obtain the following equilibrium equations:

$$
\begin{aligned}
\frac{X_{\mathrm{RCOOH}}}{X_{\mathrm{RCOOH} C_{\mathrm{H}^{+}}}} & =K_{\mathrm{RCOO}^{-}}^{\prime} \exp \left(\frac{z_{\mathrm{RCOO}^{-}} e \Psi_{0}}{k T}\right) \\
\frac{X_{(\mathrm{RCOO})_{3} \mathrm{Cr}}}{X_{\mathrm{RCOO}^{-}}^{3} C_{\mathrm{Cr}^{3+}}} & =K_{\mathrm{RCOO}^{-}}^{\prime \prime} \exp \left(\frac{z_{\mathrm{RCOO}^{-} e \Psi_{0}}}{k T}\right)
\end{aligned}
$$

where $\Psi_{0}$ is the surface potential, $e$ is the elementary charge, $z_{\mathrm{RCOO}^{-}}$is a valence, $T$ is the temperature, $k$ is the Boltzmann's constant,

$$
\begin{aligned}
X_{(\mathrm{RCOO})_{2} \mathrm{Cu}}= & \frac{n_{(\mathrm{RCOO})_{3} \mathrm{Cr}}}{3 n_{\mathrm{RCOO}^{-}}+n_{(\mathrm{RCOO})_{3} \mathrm{Cr}}}, \\
k t \ln K_{\mathrm{RCOO}^{-}}^{\prime}= & \left.\mu_{\mathrm{H}^{+}}^{\theta}(\text { solution })+\mu_{\mathrm{RCOO}^{-}}^{\theta} \text { (surface }\right) \\
& -\mu_{\mathrm{RCOOH}}^{\theta}(\text { surface }) \text { and } \\
k t \ln K_{\mathrm{RCOO}^{-}}^{\prime \prime}= & \left.\mu_{\mathrm{Cr}^{3+}}^{\theta}(\text { solution })+\mu_{\mathrm{RCOO}^{-}}^{\theta} \text { (surface }\right) \\
& -\mu_{(\mathrm{RCOO})_{3} \mathrm{Cr}}^{\theta}(\text { surface })
\end{aligned}
$$

To obtain $X_{(\mathrm{RCOO})_{3} \mathrm{Cr}}$, the effective concentration for $n_{\mathrm{RCOO}^{-}}$ is required.

Semidilute Polyelectrolyte Solutions. The configuration of a polyelectrolyte chain in a semidilute solution with added metal ions is shown in Figure 7. On sufficiently small length scales (less than the electrostatic blob size D), the polymer-solvent interactions of the $g_{e}$ monomers in each electrostatic blob depend on solvent quality. In good and $\Theta$ solvent, the electrostatic interaction energy due to charge repulsion within an electrostatic blob is on the order of thermal energy. ${ }^{23}$

$$
\left(\frac{g_{e}}{A}\right)^{2} \frac{e^{2}}{\varepsilon D} \approx k T T \geq \Theta
$$

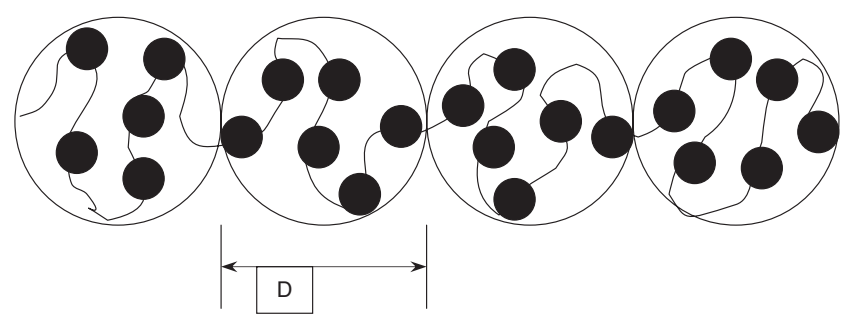

Figure 7. Polyelectrolyte conformation in semidilute solution: the chain of blobs.

Where $A$ is the average number of monomers between uncondensed charges, $e$ is the elementary charge, $\varepsilon$ is the dielectric constant of the solvent, $k$ is the Boltzmann constant, and $T$ is the temperature.

Equation 3 can be simplified using the Bjerrum length $l_{\mathrm{B}}=q^{2} /(\varepsilon k T)$. The Bjerrum length is the distance at which the energy of the Coulomb interaction between two elementary charges is equal to thermal energy.

$$
\left(\frac{g_{e}}{A}\right)^{2} l_{\mathrm{B}} \approx D T \geq \Theta
$$

On the other hand, $g_{e}$ has a certain amount of charges. The total concentration $n_{\mathrm{RCOO}^{-}}$can be written as:

$$
g_{e}=\vartheta^{\prime} n_{\mathrm{RCOO}^{-}}
$$

where $\vartheta^{\prime}$ is the proportional coefficient.

$A$ is the number of monomers between effective charges and thus incorporates any effects of counterion condensation. Therefore, we can also write:

$$
A=\vartheta^{\prime \prime} n_{\mathrm{RCOO}^{-}, \text {effect }}
$$

where $\vartheta^{\prime \prime}$ is the proportional coefficient, and $n_{\mathrm{RCOO}^{-}, \text {effect }}$ is the effective concentration of $n_{\mathrm{RCOO}^{-}}$.

The concentrations of $n_{\mathrm{RCOO}^{-}}$in equation 5 , and $n_{\mathrm{RCOO}^{-}, \text {effect }}$ in equation 6 , are substituted into equation 4 .

$$
\frac{n_{\mathrm{RCOO}^{-}, \text {effect }}}{n_{\mathrm{RCOO}^{-}}}=P(A) ; \quad \frac{\vartheta^{\prime}}{\vartheta^{\prime \prime} P(A)} \approx \sqrt{\frac{l_{\mathrm{B}}}{D}} ;
$$

where $P(A)$ is the probability factor. In the equilibrium and isotherm state of the system, we can assume that the Bjerrum length $l_{\mathrm{B}}$ is constant and the electrostatic blob size $D$ is fixed. A value $P(A)$ will be in the range of $0<P(A) \leq 1$.

Dissociation of Protons. Surfaces with acidic or basic functional groups undergo acid base reactions in aqueous media which lead to formation 1 . In low surface potentials, the surface concentration of protons is commonly approximated by the Boltzmann distribution. ${ }^{24}$ In order to fit the model on experiential data, we assumed the addition of a parameter $\chi$ into the approximation of the Boltzmann distribution as a degree of protonation:

$$
C_{\mathrm{H}^{+}, \text {effect }}=C_{\mathrm{H}^{+}}^{\chi *} \exp \left(-\frac{F \Psi_{0}}{R T}\right)
$$

where $C_{\mathrm{H}^{+} \text {,effect }}$ is the concentration of protons on the surface, $C_{\mathrm{H}^{+}}$is the $\mathrm{pH}$ of the media and $\chi$ is the assumed degree of protonation $(0<\chi \leq 1)$. 
Equilibrium Adsorption Concentration. By combining the equilibrium equation of the chemical potential of a surface group, theory of semidilute polyelectrolyte solutions, and the dissociation of protons from the VRS based on the Boltzmann distribution, we can write the equilibrium adsorption concentration as:

$$
\begin{gathered}
X_{(\mathrm{RCOO})_{3} \mathrm{Cr}}=\frac{n_{(\mathrm{RCOO})_{3} \mathrm{Cr}}}{3 P(A) n_{\mathrm{RCOO}^{-}}+n_{(\mathrm{RCOO})_{3} \mathrm{Cr}}} \\
=\frac{K_{\mathrm{RCOO}^{-}}^{\prime \prime}}{K_{\mathrm{RCOO}^{-}}^{3}} \frac{1}{C_{\mathrm{H}^{+}}^{3}} X_{\mathrm{RCOOH}^{3} C_{\mathrm{Cr}^{3+}}} \\
\frac{n_{(\mathrm{RCOO})_{2} \mathrm{Cu}}}{3 P(A) n_{\mathrm{RCOO}^{-}}+n_{(\mathrm{RCOO})_{3} \mathrm{Cr}}}=\frac{K_{\mathrm{effect}}}{27} C_{\mathrm{Cr}^{3+}} 10^{3 \times p H} \exp \left(\frac{2 F \Psi_{0}}{R T}\right)
\end{gathered}
$$

where

$$
\begin{aligned}
& K_{\text {effect }}=\frac{K_{\mathrm{RCOO}}^{\prime \prime}}{K_{\mathrm{RCOO}}^{\prime 2}} \\
& n_{\mathrm{RCOO}^{-}}=n_{\mathrm{RCOO}^{-} \cdot \max }-3 n_{\mathrm{R}(\mathrm{COO})_{3} \mathrm{Cr}}
\end{aligned}
$$

and

$$
\begin{aligned}
& X_{\mathrm{RCOOH}}=1 / 2, \quad C_{\mathrm{Cr}^{3+}}=1 \times 10^{-2} \mathrm{~mol} / \mathrm{L} \\
& T=293.45 \mathrm{~K}
\end{aligned}
$$

$n_{\mathrm{RCOO}^{-}}$means moles of chelate groups that can combine with cations. $\mathrm{Cr}^{3+}$ ion can bond with two $\mathrm{RCOO}^{-}$groups. Therefore, $n_{\mathrm{RCOO}^{-} \cdot \max }-3 n_{\mathrm{R}(\mathrm{COO})_{3} \mathrm{Cr}}$ is used for $n_{\mathrm{RCOO}^{-}}$, and $n_{\mathrm{RCOO}^{-} \text {.max }}(6.2 \mathrm{mmol})$ is the maximum metal ion adsorption mole on the VRS. This value is analogous to:

$$
\begin{gathered}
\frac{n_{(\mathrm{RCOO})_{3} \mathrm{Cr}}}{3 P(A) n_{\mathrm{RCOO}^{-} \max }-9 P(A) n_{(\mathrm{RCOO})_{3} \mathrm{Cr}}+n_{(\mathrm{RCOO})_{3} \mathrm{Cr}}} \\
=\frac{K_{\text {effect }}}{27} C_{\mathrm{Cr}^{3+}} 10^{3 x p H} \exp \left(\frac{2 F \Psi_{0}}{R T}\right)
\end{gathered}
$$

We can also derive the same equilibrium model for other metal ions such as $\mathrm{Al}^{3+}$, and $\mathrm{Fe}^{3}$ with the same initial concentration value of metal ions as found in $\mathrm{Cr}^{3+}$.

\section{The Effects of the Factors $P(A), \chi$, and $K_{\text {effect }}$ on Metal Adsorption}

The factors and surface potentials of metal ion adsorption were obtained by equilibrium modeling using the empirical data shown in Figure 6 (curves). The probability factor $P(A)$ might represent how much carboxyl groups can be available to bond with metal ions. Accordingly, the probability factors of carboxyl groups of the VRS inverse with metal ions such as $\mathrm{Al}^{3+}, \mathrm{Cr}^{3+}$, and $\mathrm{Fe}^{3+}$ were found to be 0.1099, 0.10959, and 0.10909 , respectively. Each of the values of $P(A)$ demonstrated the hindrance effect of the VRS that occurred due to the lack of effective carboxyl groups. Also, a degree of protonation was to assume protonation of the VRS in solution that could compete against metal ions adsorption. The degrees of protonation of each of adsorption obtained as $\chi=0.10354$ (Al), $\chi=0.33695$ $(\mathrm{Fe})$, and $\chi=0.38715(\mathrm{Cr})$. If a degree of protonation was low, it increased of available carboxyl groups. However, the effective ratio of surface equilibrium constants $\mathrm{Cr}^{3+}$ adsorption on the VRS, $K_{\text {effect }}=0.03617$, caused the adsorption to decrease because the surface equilibrium constant for protonation was higher than for chromium ion. The effective ratio of $\mathrm{Cr}^{3+}, K_{\text {effect }}=0.03617$, was significantly lower compared to the factor of $\mathrm{Al}^{3+} K_{\text {effect }}=0.30952$, and $\mathrm{Fe}^{3+} K_{\text {effect }}=$ 0.78282. The significant difference between $\mathrm{Cr}^{3+}$ resulted in a lower adsorption of $\mathrm{Zn}^{2+}$ compared to $\mathrm{Al}^{3+}$ and $\mathrm{Fe}^{3+}$ in same $\mathrm{pH}$ values. The surface potential, $\Psi_{0}$, of the VRS for all metal adsorptions was $-1.6296 \mathrm{mV}$ since all metal ions were considered to react with the surface on the same surface plane.

\section{CONCLUSIONS}

This study was dealt with the investigation synthesized the VRS and its physico-chemical properties. The confirmation of structures of the VRS, the VRS metal complexes were performed by ${ }^{13} \mathrm{C}$ solid state NMR and FT-IR. The peaks corresponded to carboxyl groups at $1734 \mathrm{~cm}^{-1}$, carboxyl groups with metals in the range of $1605-1639 \mathrm{~cm}^{-1}$ were certified FT-IR spectra after esterification, adsorption of metals, respectively. Thermal study was carried out by TGA that exhibited curves of weight loss of the samples with increasing temperature range of $30-700^{\circ} \mathrm{C}$. Weight residues of all the VRS metal complexes were increased compared to the VR and described in the following order: VRS-Cr $>$ VRS$\mathrm{Fe}>$ VRS-Al. The adsorption of metal on VRS increased when the $\mathrm{pH}$ increased. The maximum metal ions adsorbed could be classified as $\mathrm{Cr}^{3+}>\mathrm{Al}^{3+}>\mathrm{Fe}^{3+}$. In order to predict adsorption and the order of metals on the VRS, an equilibrium model was modified using basic chemical potentials and the Boltzmann distribution. The probability factor $P(A)$, the degree of protonation $\chi$, the effective ratio of the surface equilibrium constants $K_{\text {effect }}$, and the surface potential $\Psi_{0}$, were calculated by inserting them in a model that fit the experimental data. These factors well demonstrated the adsorption capacity of metals on the VRS. The most effective indicator was the probability factor because it clearly predicted how much carboxyl groups on the VRS were available to bond with the metal ions.

\section{NOMENCLATURE}

$A$ number of monomers between uncondensed charges

$C_{i}$ concentration of component $i(\mathrm{~mol})$

$D$ electrostatic blob size

$e$ elementary charge $(\mathrm{C})$

$F$ Faraday constant $(\mathrm{C} / \mathrm{mol})$

$g_{e}$ number of monomers in an electrostatic blob

$k$ Boltsmann constant $(\mathrm{J} / \mathrm{K})$

$K_{i}^{\prime}, K_{i}^{\prime \prime} \quad$ surface equilibrium constant

$K_{\text {effect }}$ effective ratio of surface equilibrium constants $\left(=\frac{K_{\mathrm{RCOO}-}^{\prime \prime}}{K_{\mathrm{RCOO}-}^{\prime 2}}\right)$

$l_{\mathrm{B}}$ Bjerrum length

$M$ mass of the VRS ( $\mathrm{g}$ )

$n_{i}$ mole of component $i$ (mmol)

$q_{e}$, cation exchange capacity (meq/g)

$\mathrm{R}$ shown in Fig. 1

$R$ ideal gas constant $(\mathrm{J} / \mathrm{Kmol})$ 
$T$ temperature (K)

$V_{25}$ volume sampled from the solution $\left(\mathrm{dm}^{3}\right)$

$V_{100}$ volume of the solution $\left(\mathrm{dm}^{3}\right)$

$V_{\mathrm{HCl}}$ volume of $\mathrm{HCl}$ for back titration $\left(\mathrm{dm}^{3}\right)$

$X_{i}$ mole fraction of component $i$

$z_{i}$ valency of component $i$

$\chi$ degree of protonation

$\varepsilon$ dielectric constant

$P(A)$ probability factor

$\vartheta^{\prime}, \vartheta^{\prime \prime}$ proportional coefficient

$\mu_{i}$ chemical potential of component $i$

$\mu_{i}^{e l}$ chemical potential of component $i$ considering the electrostatic contribution

$\mu_{i}^{\theta}$ chemical potential of component $i$ in the standard state

$\Theta$ theta temperature

$\Psi_{0}$ surface potential $(\mathrm{mV})$

Received: September 4, 2007 Accepted: December 17, 2007

Published: February 26, 2008

\section{REFERENCES}

1. V. Vuorio, J. A. Manzanares, L. Murtomaki, J. Hirvonen, T. Kankkunen, and K. Kontturi, J. Controlled Release, 91, 439 (2003).

2. O. A. El Seoud and T. Heinze, Adv. Polym. Sci., 186, 103 (2005).

3. K. J. Edgar, C. M. Buchanan, J. S. Debenham, P. A. Rundquist, B. D. Seiler, M. C. Shelton, and D. Tindall, Prog. Polym. Sci., 26, 1605 (2001).

4. W. M. Hosny, Polym. Int., 42, 157 (1997).

5. T. W. Swaddle, J. Rosenqvist, P. Yu, E. Bylaska, B. L. Phillips, and W. H. Casey, Science, 308, 1450 (2005).

6. M. A. S. D. Barros, A. S. Zola, P. A. Arroyo, C. R. G. Tavares, and E. F. Sousa-Aguiar, Adsorption, 12, 239 (2006).
7. C. W. MacDiarmid and R. C. Gardner, J. Biol. Chem., 273, 1727 (1998).

8. H. Jacqmin, D. Commenges, L. Letenneur, P. Barberger-Gateau, and J.-F. Dartigues, Am. J. Epidemiol., 139, 48 (1994).

9. S. Lacour, V. Deluchat, J.-C. Bollinger, and S. Bernard, Talanta, 46, 999 (1998).

10. P. M. Outridge and A. M. Scheuhammer, Rev. Environ. Contam. Toxicol., 130, 31 (1993).

11. W. N. Harrison, S. M. Bradberry, and J. A. Vale, Clinical Toxicology, 38, 137 (2000).

12. W. Lin and Y. L. Hsieh, Ind. Eng. Chem. Res., 35, 3817 (1996).

13. F. Beolchini, F. Pagnanelli, L. Toro, and F. Veglio, Water Res., 40, 144 (2006).

14. Z. Reddad, C. Gerente, Y. Andres, and P. L. Cloirec, Environ. Sci. Technol., 36, 2067 (2002).

15. A. Esposito, F. Pagnanelli, and F. Veglio, Chem. Eng. Sci., 57, 307 (2002).

16. J. Peydecastaing, S. Girardeau, C. Vaca-Garcia, and M. Borredon, Cellulose, 13, 95 (2006).

17. H. Yuksek, M. Alkan, S. Bahceci, I. Cakmak, Z. Ocak, H. Baykara, O. Aktas, and E. Agyel, J. Mol. Struct., 873142 (2008).

18. N. B. Colthup, L. H. Daly, and S. E. Wiberley, "Introduction to Infrared and Raman Spectroscopy,” Academic Press Inc, London, 1964.

19. R. V. S. Alfaya and Y. Gushikem, J. Colloid Interface Sci., 213, 438 (1999).

20. A. A. M. A. Nada and M. L. Hassan, J. Appl. Polym. Sci., 102, 1399 (2006).

21. Y. G. Ko, U. S. Choi, B. G. Ahn, and D. J. Ahn, J. Polym. Sci., Part A: Polym. Chem., 38, 2815 (2000).

22. D. F. Evans and H. Wennerstrom, "The Colloidal Domain: Where Physics, Chemistry, Biology, and Technology Meet,” 2nd ed., Wiley, New York, 1999, p 127.

23. A. V. Dobrynin, R. H. Colby, and M. Rubinstein, Macromolecules, 28, 1859 (1995).

24. R. Schweiss, P. B. Welzel, C. Werner, and W. Knoll, Langmuir, 17, 4304 (2001). 